TEACHING TACTIC

\title{
Filling the Gap with the Map
}

Jin H. Han

New York Theological Seminary

\section{The context}

Just as one can take a horse to water but cannot make him drink, so Bible teachers can lead students to the Bible, only to have them not recognize the places in which the biblical characters lived. After experimenting with a few map exercises, I realized the great contributions that maps could make to students' understanding of the history and literature of the Bible.

For decades, I have taught Old Testament at a metropolitan theological school that serves second-career students from diverse ethnic and cultural backgrounds. Most of them start their theological education after a sizable hiatus. They bring rich life experience, but many of them have little to no prior instruction in humanities, let alone geography. To help first-year students make friends with maps, I introduced the assignment of drawing a map of tenth century Judah under David and Solomon.

\section{The pedagogical purpose}

My goal is to help students read and hear the Bible as a story that takes place in time and space on earth. While they work on the map, they review the topography of the land. As one might expect, they typically color the coastal plain green and the dry terrain on the eastern side of the Judean mountains brown. Occasionally, mishaps take place; a student makes the sea dark brown or the Sea of Galilee half the page. Frequently, the Jordan becomes the river of Mark Twain's imagination, "four thousand miles long and thirty-five miles wide."

\section{Description of the strategy}

To support students, I instituted the following incremental steps. On the first day of class, I describe this assignment along with its rationale and hoped-for learning outcomes. In the fifth week, students receive further details through a prerecorded lecture that surveys the land of the Bible and highlights key locations for the kingdom of David and Solomon (e.g., Jerusalem as the capital of the United Monarchy, Hazor and Megiddo, the port of Ezion-geber). After we study the reign of David and Solomon, the class has about four weeks to complete the map assignment.

\section{Why it is effective}

The map exercise provides multiple benefits. First, while the bulk of course activities center on verbal reasoning and writing, the map assignment gives students a chance to imagine the biblical living place multidimensionally. Furthermore, the map assignment employs their sensory capabilities. Many students delight in discovering an artistic talent they never knew they had. One student enjoyed the map assignment so much that she prepared the map on a door-size wooden panel. When I asked her to reclaim her massive map from my office, she smiled and replied that I could keep it-she liked it so much that she made another one for herself. 